\title{
Visual and refractive outcomes after implantation of a fully diffractive trifocal lens
}

This article was published in the following Dove Press journal:

Clinical Ophthalmology

3I August 2012

Number of times this article has been viewed

\author{
Béatrice Cochener' \\ Jérome Vryghem ${ }^{2}$ \\ Pascal Rozot ${ }^{3}$ \\ Gilles Lesieur ${ }^{4}$ \\ Steven Heireman ${ }^{2}$ \\ Johan A Blanckaert ${ }^{5}$ \\ Emmanuel Van Acker ${ }^{6}$ \\ Sofie Ghekiere ${ }^{5}$ \\ 'Ophthalmology Department, \\ University Hospital CHU, Brest, \\ France; ${ }^{2}$ Brussels Eye Doctors, \\ Brussels, Belgium; ${ }^{3}$ Ophthalmology \\ Department, Clinique Monticelli, \\ Marseille, ${ }^{4}$ Centre Ophtalmologique \\ Iridis, Albi, France; ${ }^{5}$ Ophthalmology \\ Department, Jan Yperman Ziekenhuis, \\ leper, ${ }^{6}$ Ophthalmology Department, \\ Clinique Saint Joseph, Lobbes, Belgium
}

Correspondence: Béatrice Cochener

Ophthalmology Department,

Bâtiment 2bis, University Hospital

CHU Morvan 5, Avenue Foch,

29609 Brest Cedex, France

Tel +33298223440

Fax +33 298223440

Email beatrice.cochener@ophtalmologiechu29.fr
Background: The purpose of this study was to record the visual outcomes of patients treated by six surgeons after implantation of a trifocal lens.

Methods: The setting for this study comprised six ophthalmology units and eye clinics in Belgium and France, with a coordinating center in France, and data management and statistical analysis in France and Belgium. Ninety-four eyes from 47 patients were implanted with a trifocal FineVision ${ }^{\circledR}$ intraocular lens by six surgeons. Monocular and binocular, uncorrected and best distance-corrected, and photopic and mesopic visual acuity was measured, as well as the defocus curve between $+4 \mathrm{D}$ and $-4 \mathrm{D}$ with best distance correction.

Results: Near and far monocular visual acuities were similar to the data published after bifocal intraocular lens implantation. Intermediate vision was improved, and was demonstrated by scores of near visual acuity as well as far visual acuity with defocus $-1.5 \mathrm{D}$-add lens. Far vision is maintained in mesopic conditions.

Conclusion: The trifocal intraocular lens provides good far, intermediate, and near visual acuity.

Keywords: trifocal intraocular lens, multifocal intraocular lens, cataract surgery, diffractive intraocular lens

\section{Introduction}

Over the past 20 years, many new options that permit freedom from spectacles after cataract surgery have emerged, and could significantly reduce public health care costs. ${ }^{1}$ The options include multifocal intraocular lenses, ${ }^{2}$ which have been shown to achieve better outcomes than accommodative intraocular lenses, ${ }^{3,4}$ despite compromise in the light energy allocated to each focal point. Moreover, multifocal intraocular lenses do not decrease stereopsis, even though bifocal intraocular lens implantation simultaneously generates defocused and focused images on the retina. ${ }^{5}$ Patients have reported that diffractive intraocular lenses provide satisfactory visual comfort. ${ }^{6}$

Artigas et $\mathrm{al}^{7}$ and Maxwell et $\mathrm{al}^{8}$ have both reported that diffractive bifocal optics have a better modulation transfer function than refractive bifocal optics. Felipe et $\mathrm{al}^{9}$ also showed that modulation transfer function correlates with visual acuity. In particular, they demonstrated that the limited modulation transfer function peak at $1.5 \mathrm{D}$ corresponding to intermediate vision is responsible for the poor intermediate vision outcomes of bifocal intraocular lenses. Indeed, up until now, diffractive multifocal intraocular lenses were only bifocal, with a focus allocated to far vision and another allocated to near vision. Depending on the depth of field and the addition power chosen for near vision, these intraocular lenses do provide some intermediate visual 
acuity, that nevertheless remains inadequate, ${ }^{10-14}$ as observed by Felipe et al. ${ }^{9}$

FineVision $^{\circledR}$ (Physiol, Liege, Belgium) is a diffractive implant with three focal points for far, intermediate, and near vision. Because this optic design is completely new and because it is necessary to assess the independence of this intraocular lens with respect to surgeon skills and measurements, we report here the early results after implantation of the FineVision intraocular lens by six surgeons.

\section{Materials and methods Study design}

This was a prospective, nonrandomized, observational study. The research follows the tenets of the Declaration of Helsinki, and an institutional review board approved the protocol. Data for the first 47 patients implanted with the FineVision intraocular lens are presented here. Prior to implantation, all patients were warned of the risks associated with multifocal intraocular lenses and informed that their ophthalmological data would be analyzed.

\section{Intraocular lens}

The FineVision is a multifocal aspheric intraocular lens made of $25 \%$ hydrophilic material with a yellow chromophore embedded in the matrix polymer (Figure 1). The singlepiece 4-loop haptics intraocular lens has a total diameter of $10.75 \mathrm{~mm}$, an optic body diameter of $6.15 \mathrm{~mm}$, and 5 degrees of haptic angulation. The FineVision is a fully diffractive

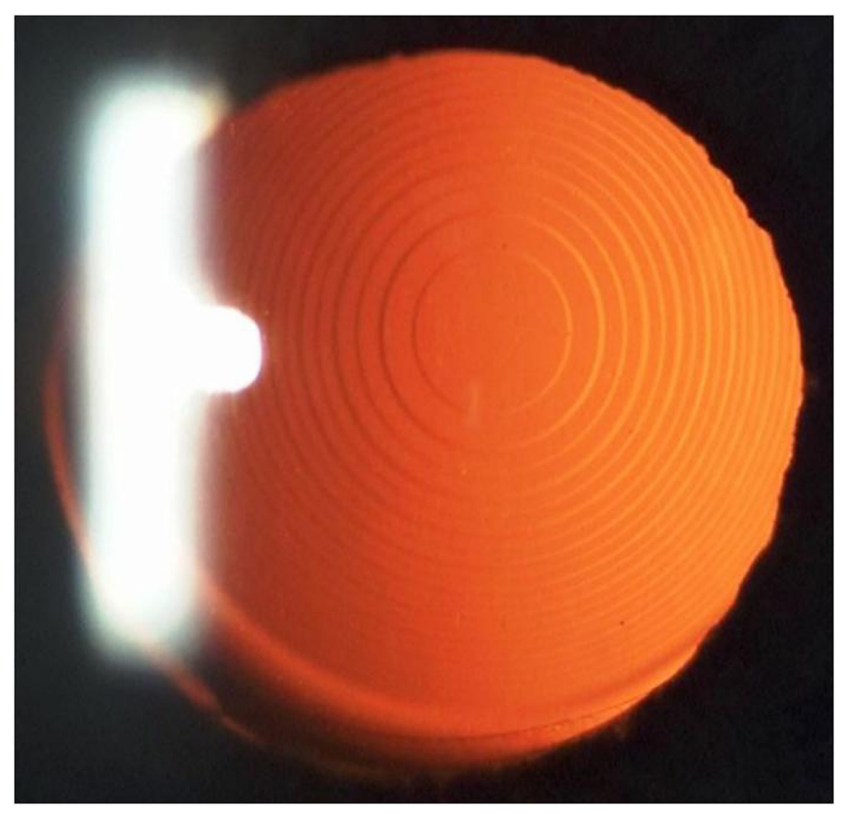

Figure I Slit lamp photograph of a patient eye implanted with the FineVision ${ }^{\circledR}$ intraocular lens. intraocular lens that combines two diffractive gratings, one with $\mathrm{a}+1.75 \mathrm{D}$ addition and one with $\mathrm{a}+3.5 \mathrm{D}$ addition. ${ }^{15}$ Its optic is designed to allocate $43 \%$ of the light energy to far vision, $28 \%$ to near vision, and $15 \%$ to intermediate vision, at a $3 \mathrm{~mm}$ pupil aperture. The remaining 14\% of light energy is lost, but this is a minimal loss when compared with the energy lost by other diffractive patterns (18\% for standard bifocal diffractive intraocular lenses). To improve night vision, the distribution of light energy varies with pupil aperture, favoring far vision for larger pupils. Available spherical powers range from $10 \mathrm{D}$ to $30 \mathrm{D}$ in $0.5 \mathrm{D}$ increments. An A constant (SRK/T) of 118.9 (interferometry) has been used.

\section{Patients}

In total, 47 patients (94 eyes) were bilaterally implanted with the FineVision intraocular lens between March 2010 and November 2010 during standard cataract surgery. Depending on the surgeon, different incision sizes were used (Table 1).

\section{Preoperative examination}

Preoperative investigations consisted of a slit-lamp examination, assessment of visual acuity, measurements of intraocular pressure and axial length, and keratometry. All patients requested independence from spectacles and were informed in detail about the possibility of multifocal intraocular lens implantation. Patients with ocular comorbidity or corneal astigmatism greater than $0.75 \mathrm{D}$ were excluded from implantation.

\section{Postoperative follow-up}

Postoperative follow-up consisted of measuring monocular and binocular uncorrected visual acuity and best distancecorrected visual acuity for far, intermediate, and near vision under scotopic conditions (500 lux). Distance visual acuity was assessed in decimals using Early Treatment Diabetic Retinopathy Study (ETDRS) charts. Near and intermediate visual acuities were assessed using a Parinaud near visual chart at $35 \mathrm{~cm}$ and $65 \mathrm{~cm}$, respectively. The Parinaud chart is a scale from 1 to 14 which is proportional to the minimum

Table I Number of eyes implanted by each surgeon, and incision size that each used

\begin{tabular}{lll}
\hline Surgeon & Implanted eyes $(\mathbf{n})$ & Incision size $(\mathbf{m m})$ \\
\hline PR & 20 & $1.8-2.2$ \\
JV & 12 & 1.9 \\
GL & 20 & 1.8 \\
BC & 30 & 1.8 \\
JB & 8 & 2.4 \\
EVA & 4 & 2.2 \\
\hline
\end{tabular}


Table 2 Preoperative clinical data

\begin{tabular}{lrll}
\hline & Mean \pm SD & Range & Eyes (n) \\
\hline Intraocular pressure (mmHg) & $14.63 \pm 2.57$ & $10-20$ & 91 \\
Visual acuity (decimal) & $0.72 \pm 0.25$ & $0.16-1$ & 89 \\
Visual acuity (logMAR) & $0.18 \pm 0.19$ & $0.80-0.00$ & 89 \\
Axial length (mm) & $23.13 \pm 1.17$ & $20.53-26.15$ & 89 \\
Mean corneal K readings (D) & $43.77 \pm 1.32$ & $41.13-46.75$ & 90 \\
Mean corneal astigmatism (D) & $-0.40 \pm 0.23$ & $-1.29-0$ & 90 \\
Intraocular lens power (D) & $21.69 \pm 3.15$ & $12-30$ & 94 \\
\hline
\end{tabular}

Abbreviations: SD, standard deviation; MAR, minimum angle of resolution.

angle of resolution (MAR) measurement (score 1 is best). Binocular best distance-corrected defocus curves were performed using ETDRS charts and addition lenses ranging from $4 \mathrm{D}$ to $-4 \mathrm{D}$ with incremental steps of $0.5 \mathrm{D}$.

Four surgeons (PR, JV, BC, JB) also assessed monocular and binocular visual acuities for far, intermediate, and near vision in mesopic conditions (10 lux). In addition, two surgeons (JCV, GL) assessed contrast vision by measuring visual acuity at $25 \%$ and $10 \%$ contrast. The acronyms for the different testing conditions of the visual acuity are given by the Kohnen. ${ }^{16}$ Illumination conditions were controlled using the Amprobe LM-120 light meter (Amprobe Test Tools, Everett, FL). Lighting conditions and charts were kept identical for all surgeons, so that all patients would have equal potential for visual and refractive outcome. Standard clinical tests, including measurement of intraocular pressure and slit-lamp examinations, were also performed. All surgeons were alert for adverse visual events such as halos, ghosting images, or glare, and recorded these events when they were observed.

\section{Statistical analysis}

Descriptive statistics were performed by means of average, standard deviation, median, minimum and maximum, and box plots using Excel and Analyse-it Excel addin (Analyse-it Software Ltd, Leeds, UK).

\section{Results}

The patient population comprised 26 females and 21 males. The mean patient age at surgery was $64 \pm 8$ years. Mean preoperative visual data are listed in Table 2. Mean interval between implantation of the first and second eyes was about one month. In one case, one haptic broke during injection. The intraocular lens was nevertheless well centered and remained stable over time. No other peroperative complication was reported. Figure 1 shows an example of the intraocular lens after implantation.

After about one week (11 \pm 14 days), mean intraocular pressure was $13.9 \pm 1.7 \mathrm{mmHg}$, mean uncorrected visual acuity was $\log$ MAR $0.08 \pm 0.10$, and mean best spectaclecorrected visual acuity was $\log$ MAR $0.03 \pm 0.05$. One patient was lost to follow-up after 2 weeks. At the last consultation, his visual acuity was $\log$ MAR 0.04 and $\log$ MAR 0.1 .

After 6 months, the average intraocular pressure was $13.4 \pm 1.7 \mathrm{mmHg}$. Tables $3-5$ show monocular visual and refractive outcomes, binocular visual and refractive outcomes, and mesopic monocular and binocular outcomes, respectively. The values are summarized and compared in the box plot in Figure 2. This graph clearly shows that using the best distance correction demonstrated consistent outcomes around the average. The binocular uncorrected defocus curve is shown in Figure 3. There is a continuum in visual acuity, with a slight decrease between far and near vision due to the fact that lighting conditions stayed the same during the whole measurement. The mean best distance-corrected binocular visual acuity was $\log$ MAR $0.03 \pm 0.06$ with $25 \%$ contrast

Table 3 Monocular visual and refractive outcomes

\begin{tabular}{|c|c|c|c|c|c|c|c|c|}
\hline & \multicolumn{4}{|c|}{ Uncorrected } & \multicolumn{4}{|c|}{ Best distance-corrected } \\
\hline & 3 months & & 6 months & & 3 months & & 6 months & \\
\hline \multicolumn{9}{|c|}{ Distance visual acuity } \\
\hline Decimal & $0.86 \pm 0.19$ & 90 eyes & $0.86 \pm 0.19$ & 92 eyes & $0.93 \pm 0.13$ & 91 eyes & $0.94 \pm 0.13$ & 91 eyes \\
\hline LogMAR & $0.08 \pm 0.11$ & & $0.08 \pm 0.12$ & & $0.03 \pm 0.06$ & & $0.03 \pm 0.06$ & \\
\hline \multicolumn{9}{|c|}{ Intermediate visual acuity } \\
\hline Parinaud & $2.90 \pm 1.53$ & 82 eyes & $2.97 \pm 1.58$ & 82 eyes & $2.81 \pm 1.31$ & 89 eyes & $2.90 \pm 1.34$ & 83 eyes \\
\hline LogMAR & $0.08 \pm 0.11$ & & $0.08 \pm 0.12$ & & $0.07 \pm 0.10$ & & $0.08 \pm 0.10$ & \\
\hline \multicolumn{9}{|c|}{ Near visual acuity } \\
\hline Parinaud & $2.04 \pm 0.90$ & 90 eyes & $2.03 \pm 0.87$ & 86 eyes & $1.92 \pm 0.69$ & 91 eyes & $1.91 \pm 0.61$ & 91 eyes \\
\hline LogMAR & $0.01 \pm 0.07$ & & $0.01 \pm 0.06$ & & $0.00 \pm 0.05$ & & $0.00 \pm 0.05$ & \\
\hline $\begin{array}{l}\text { Spherical } \\
\text { equivalent (D) }\end{array}$ & $0.03 \pm 0.43$ & 88 eyes & & & & & $0.08 \pm 0.43$ & 86 eyes \\
\hline
\end{tabular}

Abbreviation: MAR, minimum angle of resolution. 
Table 4 Binocular distance, and intermediate and near visual acuity

\begin{tabular}{|c|c|c|c|c|c|c|c|c|}
\hline & \multicolumn{4}{|c|}{ Uncorrected } & \multicolumn{4}{|c|}{ Best distance-corrected } \\
\hline & \multicolumn{2}{|l|}{3 months } & \multicolumn{2}{|l|}{6 months } & \multicolumn{2}{|l|}{3 months } & \multicolumn{2}{|l|}{6 months } \\
\hline \multicolumn{9}{|c|}{ Distance visual acuity } \\
\hline Decimal & $0.97 \pm 0.19$ & 45 patients & $0.98 \pm 0.19$ & 45 patient & $1.01 \pm 0.17$ & 44 patients & $1.01 \pm 0.17$ & 44 patients \\
\hline LogMAR & $0.02 \pm 0.09$ & & $0.02 \pm 0.09$ & & $0.00 \pm 0.07$ & & $0.00 \pm 0.07$ & \\
\hline \multicolumn{9}{|c|}{ Intermediate visual acuity } \\
\hline Parinaud & $2.51 \pm 1.02$ & 40 patients & $2.61 \pm 1.13$ & 40 patients & $2.52 \pm 1.27$ & 41 patients & $2.55 \pm 1.25$ & $4 \mid$ patients \\
\hline LogMAR & $0.05 \pm 0.08$ & & $0.05 \pm 0.08$ & & $0.05 \pm 0.09$ & & $0.05 \pm 0.09$ & \\
\hline \multicolumn{9}{|c|}{ Near visual acuity } \\
\hline Parinaud & $1.80 \pm 0.54$ & 44 patients & $1.81 \pm 0.54$ & 44 patients & $1.78 \pm 0.56$ & 44 patients & $1.79 \pm 0.55$ & 44 patients \\
\hline LogMAR & $-0.01 \pm 0.04$ & & $0.00 \pm 0.04$ & & $-0.01 \pm 0.04$ & & $-0.01 \pm 0.04$ & \\
\hline
\end{tabular}

Abbreviation: MAR, minimum angle of resolution.

and $\log$ MAR $0.12 \pm 0.10$ with $10 \%$ contrast. None of the patients reported seeing ghosting images.

\section{Discussion}

The present paper describes the clinical results after implantation of the FineVision intraocular lens in the first 47 patients. In particular, the study focused on the ability of the brain to use a third focal point by testing vision at $65 \mathrm{~cm}$ and at $4 \mathrm{~m}$ with $\mathrm{a}-1.0 \mathrm{D}$ to $-1.5 \mathrm{D}$ addition. Indeed, optical bench studies have shown that the FineVision intraocular lens provides a third focal point. ${ }^{15}$

Notably, unremarkable outcomes were reported by the only peer-reviewed publication on a trifocal intraocular lens (MIOL-Record lens) that is currently available. ${ }^{17}$ In their report, mean distance-corrected decimal visual acuity was $0.86 \pm 0.23$ and mean distance-corrected near decimal visual acuity was $0.89 \pm 0.12$, and the distance-corrected intermediate decimal visual acuity of $0.6 \pm 0.2$ did not improve with respect to reported outcomes with bifocal intraocular lenses.

This was very important to check the safety (the ability to give good near and intermediate vision) and efficiency (by enhancing the intermediate vision) of the FineVision IOL.
The study was not designed with a control group because no standard exists in the form of a trifocal intraocular lens. Furthermore, a large number of studies on bifocal intraocular lenses have already been done and can be used as a control group. Table 6 summarizes the studies of bifocal intraocular lenses in which intermediate visual acuity was tested.

Qualitative comparison of the far, intermediate, and near visual acuity of the FineVision intraocular lens with previously published outcomes of bifocal diffractive intraocular lenses (Table 6) can be made. ${ }^{14}$ The FineVision intraocular lens seems to improve intermediate visual acuity in comparison with other studies, without decreasing the capacity for near vision and slightly decreasing or improving far vision, depending on the studies.

We have not corrected intermediate visual acuity with a working distance of $65 \mathrm{~cm}$, as proposed by De Vries et al. ${ }^{12}$ This can be done by dividing by 2 the MAR scores as the optotype is twice further, that is removing $\log 2$ to the $\log$ MAR scores in intermediate vision.

Holladay and Prager $^{19}$ stated that decimal visual acuity should not be averaged because the steps between lines are not equivalent. We have expressed all our data in $\log \mathrm{MAR}$, which is recognized as the standard, standard deviation

Table 5 Monocular and binocular visual acuity in mesopic conditions for far, intermediate, and near vision

\begin{tabular}{|c|c|c|c|c|c|c|}
\hline \multirow{2}{*}{$\begin{array}{l}\text { Visual acuity in } \\
\text { mesopic conditions }\end{array}$} & \multicolumn{3}{|l|}{3 months } & \multicolumn{3}{|l|}{6 months } \\
\hline & $\begin{array}{l}\text { Decimal (far) or Parinaud } \\
\text { (intermediate and near) }\end{array}$ & LogMAR & $\begin{array}{l}\text { Eye } \\
(n)\end{array}$ & $\begin{array}{l}\text { Decimal (far) or Parinaud } \\
\text { (intermediate and near) }\end{array}$ & LogMAR & $\begin{array}{l}\text { Eye } \\
\text { (n) }\end{array}$ \\
\hline CDVA & $0.92 \pm 0.12$ & $0.04 \pm 0.06$ & 64 & $0.92 \pm 0.12$ & $0.04 \pm 0.06$ & 64 \\
\hline DCIVA & $3.86 \pm 1.39$ & $0.15 \pm 0.10$ & 64 & $3.86 \pm 1.39$ & $0.15 \pm 0.10$ & 64 \\
\hline DCNVA & $2.89 \pm 1.09$ & $0.08 \pm 0.08$ & 64 & $2.89 \pm 1.09$ & $0.08 \pm 0.08$ & 64 \\
\hline Binocular CDVA & $0.93 \pm 0.10$ & $0.03 \pm 0.10$ & 26 & $0.93 \pm 0.10$ & $0.03 \pm 0.10$ & 26 \\
\hline Binocular DCIVA & $3.86 \pm 1.82$ & $0.15 \pm 0.14$ & 26 & $3.86 \pm 1.82$ & $0.15 \pm 0.14$ & 26 \\
\hline Binocular DCNVA & $2.94 \pm 0.90$ & $0.08 \pm 0.07$ & 26 & $2.94 \pm 0.90$ & $0.08 \pm 0.07$ & 26 \\
\hline
\end{tabular}

Abbreviations: CDVA, corrected distance visual acuity; DCIVA, distance-corrected intermediate visual acuity; DCNVA, distance-corrected near visual acuity; MAR, minimum angle of resolution. 


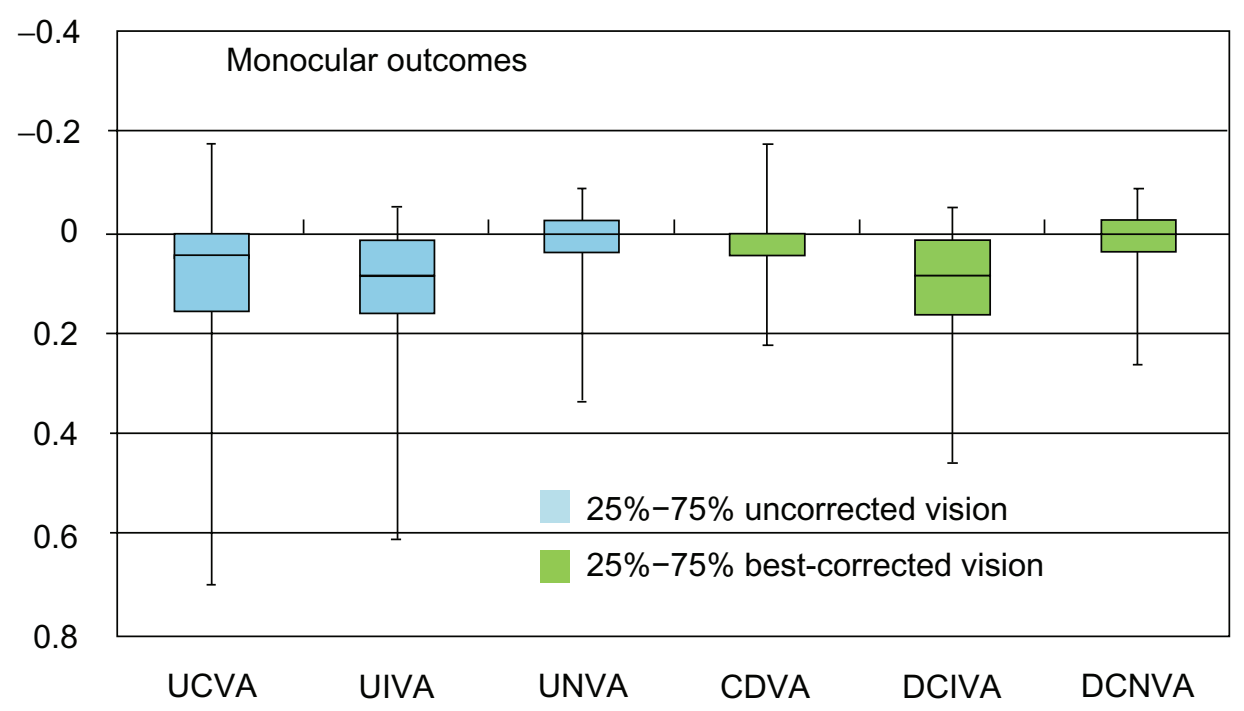

Figure 2 Box plot of the uncorrected and distance-corrected distance, intermediate and near visual acuity.

Abbreviations: UCVA, uncorrected visual acuity; UIVA, uncorrected intermediate visual acuity; UNVA, uncorrected near visual acuity; CDVA, corrected distance visual acuity; DCIVA, distance-corrected intermediate visual acuity; DCNVA, distance corrected near visual acuity.

of the decimal visual acuity as it remains for most surgeons and in half of the publications the use.

One could argue that the binocular defocus curve does not give accurate information about the bifocality or trifocality of the lens because a patient with monovision (emmetropic eye and myopic eye) with presbyopia or monofocal lens (without accommodation capacity) in a binocular defocus curve would give two apparent foci. Nevertheless, most of publications give the binocular defocus curve, except de Vries et $\mathrm{al}^{12}$ and Schmidinger et al. ${ }^{22}$ When compared with bilateral defocus curves obtained after bifocal intraocular implantation, vision in the intermediate range seems to be improved because the usual decrease of the intermediate range of visual acuity is not observed here.

The FineVision intraocular lens was designed to work in conjunction with the pupil aperture. ${ }^{15}$ This was clearly demonstrated in vivo, because far vision is kept while near vision and intermediate vision decrease in mesopic conditions (Table 5). The FineVision showed outcomes similar to that of a bifocal intraocular lens for the low-contrast ETDRS tests. Indeed, Toto et $\mathrm{al}^{11}$ found a mean visual acuity of $\log$ MAR $0.40 \pm 0.18$ with the Tecnis ZM900 $+4 \mathrm{D}$ fully diffractive intraocular lens and $\log$ MAR $0.33 \pm 0.09$ with the partially diffractive Acrysof Restor $+3 \mathrm{D}$ under

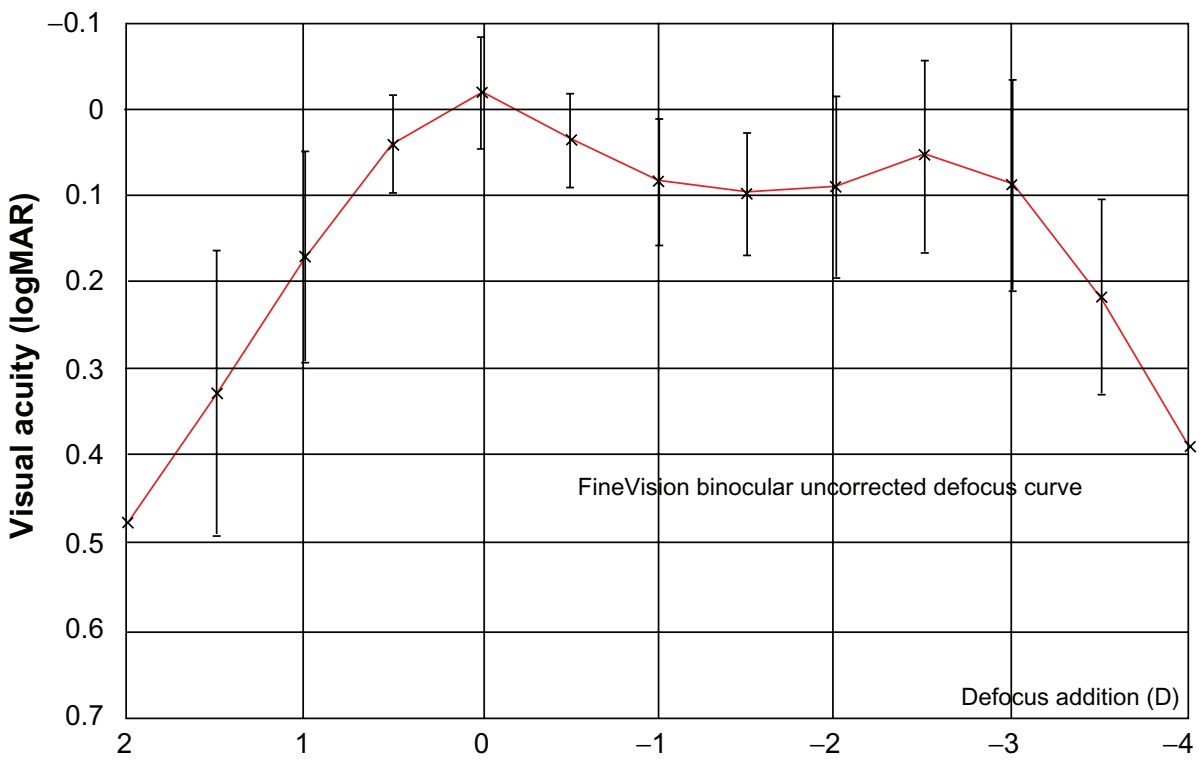

Figure 3 The FineVision binocular best distance-corrected defocus curve (binocular outcomes of 27 patients). 
Table 6 Visual outcomes of diffractive intraocular lenses in different studies

\begin{tabular}{|c|c|c|c|c|c|c|c|c|}
\hline \multirow[b]{2}{*}{ Alcon Acrysof +4 D } & \multirow[b]{2}{*}{ Alfonso et $\mathrm{al}^{14}$} & \multicolumn{2}{|c|}{ CDVA (logMAR) } & \multicolumn{2}{|c|}{ DCIVA (logMAR) } & \multicolumn{2}{|c|}{ DCNVA (logMAR) } & \multirow{2}{*}{$\begin{array}{l}\text { Eyes } \\
20\end{array}$} \\
\hline & & $-0.08 \pm 0.1$ & Binocular & $0.15 \pm 0.19$ & Binocular & $-0.05 \pm 0.06$ & Binocular & \\
\hline Alcon Acrysof +4 D* & Alfonso et $\mathrm{al}^{14}$ & $-0.1 \pm 0.1 *$ & Binocular & $0.3 \pm 0.1^{*}$ & Binocular & $0 \pm 0.15^{*}$ & Binocular & 20 \\
\hline Alcon Acrysof +4 D & De Vries et al ${ }^{12}$ & $-0.01 \pm 0.06$ & Monocular & $0.31 \pm 0.13$ & Monocular & $0.14 \pm 0.11$ & Monocular & 46 \\
\hline Alcon Acrysof $+4 D^{*}$ & De Vries et $\mathrm{al}^{12}$ & $0.05^{*}$ & & $0.4^{*}$ & & $0.15^{*}$ & & 46 \\
\hline Alcon Acrysof +4 D & Blaylock et $\mathrm{al}^{10}$ & $0.00 \pm 0.05$ & Monocular & $0.36 \pm 0.1$ & Monocular & $0.07 \pm 0.08$ & Monocular & 37 \\
\hline Alcon Acrysof $+3 \mathrm{D}$ & Alfonso et $\mathrm{al}^{14}$ & $-0.06 \pm 0.05$ & Binocular & $0.02 \pm 0.13$ & Binocular & $-0.08 \pm 0.04$ & Binocular & 20 \\
\hline Alcon Acrysof $+3 D^{*}$ & Alfonso et $\mathrm{al}^{14}$ & $-0.1 \pm 0.1 *$ & Binocular & $0.25 \pm 0.1 *$ & Binocular & $-0.05 \pm 0.1^{*}$ & Binocular & 20 \\
\hline Alcon Acrysof +3 D & De Vries et $\mathrm{al}^{12}$ & $-0.04 \pm 0.09$ & Monocular & $0.19 \pm 0.2$ & Monocular & $0.08 \pm 0.11$ & Monocular & 68 \\
\hline Alcon Acrysof $+3 D^{*}$ & De Vries et al ${ }^{12}$ & $-0.05^{*}$ & & $0.2^{*}$ & & 0.05 & & 68 \\
\hline Alcon Acrysof +3 D & Alió et al ${ }^{18}$ & $0.10 \pm 0.13$ & Monocular & & & $0.11 \pm 0.14$ & Monocular & \\
\hline Zeiss AcriLISA +3.75 D & Alfonso et $\mathrm{al}^{14}$ & $-0.08 \pm 0.08$ & Binocular & $0.15 \pm 0.15$ & Binocular & $-0.02 \pm 0.08$ & Binocular & 20 \\
\hline Zeiss AcriLISA +3.75 D* & Alfonso et $\mathrm{al}^{14}$ & $-0.1 \pm 0.1 *$ & Binocular & $0.3 \pm 0.1^{*}$ & Monocular & $0 \pm 0.15^{*}$ & Monocular & 20 \\
\hline Zeiss AcriLISA +3.75 D & Alió et al ${ }^{18}$ & $0.04 \pm 0.09$ & Monocular & $0.3(*)$ & & $0.17 \pm 0.34$ & Monocular & \\
\hline Zeiss AcriLISA +3.75 D & Can et $\mathrm{al}^{21}$ & $0.01 \pm 0.02$ & & $0.14 \pm 0.06$ & & $0.06 \pm 0.20$ & & \\
\hline Reviol +3.75 D & Can et $\mathrm{al}^{21}$ & $0.02 \pm 0.05$ & & $0.11 \pm 0.07$ & & $0.01 \pm 0.03$ & & \\
\hline Present study & & $0.03 \pm 0.06$ & & $0.08 \pm 0.10$ & & $0.00 \pm 0.05$ & & 90 \\
\hline AMO Tecnis ZM900 & Toto et al" & $-0.01 \pm 0.08$ & Monocular & $0.3^{*}$ & & $0.04^{*}$ & & 14 \\
\hline $\begin{array}{l}\text { MIOL-RECORD-3 } \\
\text { (decimal notation) }\end{array}$ & Voskresenskaya ${ }^{17}$ & $0.86 \pm 0.23$ & & $0.6 \pm 0.2$ & & $0.89 \pm 0.12$ & & 36 \\
\hline
\end{tabular}

Note: *Indicates that the number was extracted from the published defocus curve.

Abbreviations: CDVA, corrected distance visual acuity; DCIVA, distance-corrected intermediate visual acuity; DCNVA, distance-corrected near visual acuity; MAR, minimum angle of resolution.

$10 \%$ contrast. De Vries et al ${ }^{12}$ found $\log$ MAR $0.01 \pm 0.09$ under $25 \%$ contrast and $\log$ MAR $0.10 \pm 0.13$ under $10 \%$ contrast with the Acrysof Restor $+3 \mathrm{D}$. They found $\log \mathrm{MAR}$ $0.07 \pm 0.05$ (25\% contrast) and $\log$ MAR $0.16 \pm 0.08(10 \%$ contrast) with the Acrysof Restor $+4 \mathrm{D}$. This outcome was expected because half of the energy for the intermediate focal point is recovered from the lost energy of the bifocal diffractive profile. ${ }^{15}$

\section{Conclusion}

The outcomes of the present study show that there is a real intermediate vision after implantation of the FineVision lens with no loss of far and near vision. Nevertheless, they suggest that the brain can effectively use a third focal point. It has been proposed that the outcomes of multifocal intraocular lenses can improve over time due to neuroadaptation and brain plasticity. ${ }^{20}$ However, in our opinion, there is some confusion regarding refractive and diffractive intraocular lenses. Because the outcomes of refractive intraocular lens (with concentric rings) have a pupil dependence, neural adaptation to these intraocular lenses involves learning to control the pupil aperture. In contrast, with fully diffractive intraocular lenses, the image is focused whatever the pupil diameter. Nevertheless, the patient must become accustomed to the blurred intermediate vision zone, which is another form of neural adaptation. The clinical defocus curve of the
FineVision intraocular lens reveals that the image it obtains is sharp at any focal distance. Thus, this paper shows that, over a very short period of time, patients can use all of the possibilities of the FineVision intraocular lens, namely the three focal points, in photopic and mesopic conditions. Outcomes after a longer time will be published, but we considered it very important to publish an interim analysis of the pilot study, given that the FineVision is the first trifocal diffractive intraocular lens.

\section{Disclosure}

The authors report no conflicts of interest in this work.

\section{References}

1. Maxwell WA, Waycaster CR, D'Souza AO, Meissner BL, Hileman K. A United States cost-benefit comparison of an apodized, diffractive, presbyopia-correcting, multifocal intraocular lens and a conventional monofocal lens. J Cataract Refract Surg. 2008;34(11):1855-1861.

2. De Vries NE, Webers CA, Montés-Micó R, et al. Long-term follow-up of a multifocal apodized diffractive intraocular lens after cataract surgery. $J$ Cataract Refract Surg. 2008;34(9):1476-1482.

3. Saiki M, Negishi K, Dogru M, Yamaguchi T, Tsubota K. Biconvex posterior chamber accommodating intraocular lens implantation after cataract surgery: long-term outcomes. J Cataract Refract Surg. 2010;36(4):603-608.

4. Yuen L, Trattler W, Boxer-Wachler BS. Two cases of Z syndrome with the Crystalens after uneventful cataract surgery. J Cataract Refract Surg. 2008;34(11):1986-1989.

5. Ferrer-Blasco T, Madrid-Costa D, García-Lázaro S, Cerviño A, MontésMicó R. Stereopsis in bilaterally multifocal pseudophakic patients. Graefes Arch Clin Exp Ophthalmol. 2011;249(2):245-251. 
6. Cochener B, Fernández-Vega L, Alfonso JF, et al. Spectacle independence and subjective satisfaction of ReSTOR multifocal intraocular lens after cataract or presbyopia surgery in two European countries. Clin Ophthalmol. 2010;4:81-99.

7. Artigas JM, Menezo JL, Peris C, Felipe A, Díaz-Llopis M. Image quality with multifocal intraocular lenses and the effect of pupil size: comparison of refractive and hybrid refractive-diffractive designs. J Cataract Refract Surg. 2007;33(12):2111-2117.

8. Maxwell WA, Lane SS, Zhou F. Performance of presbyopia-correcting intraocular lenses in distance optical bench tests. J Cataract Refract Surg. 2009;35(1):166-171.

9. Felipe A, Pastor F, Artigas JM, et al. Correlation between optics quality of multifocal intraocular lenses and visual acuity: tolerance to modulation transfer function decay. J Cataract Refract Surg. 2010;36(4):557-562.

10. Blaylock JF, Si Z, Vickers C. Visual and refractive status at different focal distances after implantation of the ReSTOR multifocal intraocular lens. J Cataract Refract Surg. 2006;32(9):1464-1473.

11. Toto L, Falconio G, Vecchiarino L, et al. Visual performance and biocompatibility of 2 multifocal diffractive IOLs: six-month comparative study. J Cataract Refract Surg. 2007;33(8):1419-1425.

12. De Vries NE, Webers CA, Montés-Micó R, et al. Visual outcomes after cataract surgery with implantation of a $+3.00 \mathrm{D}$ or $+4.00 \mathrm{D}$ aspheric diffractive multifocal intraocular lens: comparative study. J Cataract Refract Surg. 2010;36(8):1316-1322.

13. Blaylock JF, Si Z, Prescott C, Aitchison S. Intermediate optimization of vision with bilateral nonaspheric multifocal intraocular lens implantation. J Cataract Refract Surg. 2009;35(2):303-311.
14. Alfonso JF, Fernández-Vega L, Puchades C, Montés-Micó R. Intermediate visual function with different multifocal intraocular lens models. J Cataract Refract Surg. 2010;36(5):733-739.

15. Gatinel D, Pagnoulle C, Houbrechts Y, Gobin L. Design and qualification of a diffractive trifocal optical profile for intraocular lenses. J Cataract Refract Surg. 2011;37(11):2060-2067.

16. Kohnen T. New abbreviations for visual acuity values. J Cataract Refract Surg. 2009;35(7):1145.

17. Voskresenskaya A, Pozdeyeva N, Pashtaev N, et al. Initial results of trifocal diffractive IOL implantation. Graefes Arch Clin Exp Ophthalmol. 2010;248(9):1299-1306.

18. Alió JL, Piñero DP, Plaza-Puche AB, et al. Visual and optical performance with two different diffractive multifocal intraocular lenses compared to a monofocal lens. J Refract Surg. 2011;27(8):570-581.

19. Holladay JT, Prager TC. Mean visual acuity. Am J Ophthalmol. 1991;111:372-374.

20. Pepin SM. Neuroadaptation of presbyopia-correcting intraocular lenses. Curr Opin Ophthalmol. 2008;19(1):10-12.

21. Can I, Bostancı Ceran B, Soyugelen G, Takmaz T. Comparison of clinical outcomes with 2 small-incision diffractive multifocal intraocular lenses. J Cataract Refract Surg. 2012;38(1):60-67.

22. Schmidinger G, Geitzenauer W, Hahsle B, Klemen UM, Skorpik C, Pieh S Depth of focus in eyes with diffractive bifocal and refractive multifocal intraocular lenses. J Cataract Refract Surg. 2006;32(10):1650-1656.
Clinical Ophthalmology

\section{Publish your work in this journal}

Clinical Ophthalmology is an international, peer-reviewed journal covering all subspecialties within ophthalmology. Key topics include: Optometry; Visual science; Pharmacology and drug therapy in eye diseases; Basic Sciences; Primary and Secondary eye care; Patient Safety and Quality of Care Improvements. This journal is indexed on

Submit your manuscript here: http://www.dovepress.com/clinical-ophthalmology-journal

\section{Dovepress}

PubMed Central and CAS, and is the official journal of The Society of Clinical Ophthalmology (SCO). The manuscript management system is completely online and includes a very quick and fair peer-review system, which is all easy to use. Visit http://www.dovepress.com/ testimonials.php to read real quotes from published authors. 